\title{
Knee biomechanics during squat rising with patella alta and after distal transfer of tibial tubercular surgery
}

\author{
N. Ekin AKALAN ${ }^{\mathrm{a}}$, Yener TEMELLII ${ }^{\mathrm{b}}$, Mehmet ÖZKAN ${ }^{\mathrm{c}}$
}

\begin{abstract}
Objective: Patella alta has commonly seen in prior adolescent cerebral palsy population with crouch gait pattern. Unfortunately, for the treatments of patella alta and crouch gait, the outcomes of physical therapy, orthotic and surgical treatments are highly questionable. The purpose of this study was to investigate the effects of patella alta on knee biomechanics and to analyze the benefits of distal transfer of tibial tubercule (DTTTS) during dual limb knee squat extension. Methods: A three-dimensional dynamic knee model comprising patellofemoral and tibiofemoral joints was developed. Patellar tendon length was increased $25 \%$ and $50 \%$ of its original length to simulate the pathology. Tibiofemoral and patellofemoral contact forces, loads on ligament bundles, tibial rotations and quadriceps efficiencies were compared for pathology, normal and after DTTTS. Results: The results showed that, as pattelar tendon elongation, the medial tibiofemoral contact force between $10^{\circ}$ to $20^{\circ}$ knee extension and the lateral tibiofemoral contact force between $17^{\circ}$ to $30^{\circ}$ increased gradually. It altered the neutral tension of ligament bundles, reduces the medio-lateral knee stability between $0^{\circ}$ to $17^{\circ}$ and increases the patello-femoral contact force and the efficiency of the quadriceps muscle during squat rising. Even though DTTTS normalized some of the biomechanical alterations, internal rotation in higher flexion angles, valgus-varus rotation of the tibia and the tension of aACL and PCL remained different than normal. Conclusion: These alterations may play a contributory role to develop cartilage degeneration on tibiofemoral and patellofermoral joints. Inadequate quadriceps force and abnormal loading pattern on some of the ligaments may also contribute to the recurrence mechanism of crouch gait after DTTTS surgery.
\end{abstract}

Keywords: Ligament, knee, squat, patella alta, patellar tendon, three-dimensional model

Yüksekte patellası olan bir dizin tibial tüberkülün distale transfer cerrahisi sonrası squat ekstansiyon sırasındaki biyomekanik değişiklikleri

ÖZET

Amaç: Patella alta, çömelme yürüyüş paterni olan büyük ölçüde ergen serebral palsi popülasyonunda yaygın olarak görülmektedir. Ne yazık ki patella alta ve çömelme yürüyüşünün tedavileri için fizik tedavi, ortez ve cerrahi tedavilerin sonuçları oldukça kuşkuludur. Bu çalışmanın amacı, patella alta'nın diz biyomekaniğine olan etkilerini araştırmak ve çift bacakla çömelmeden diz ekstansiyonu sırasında tibial tüberkülün (DTTTS) distal transferinin faydalarını incelemektir. Yöntem: Bu nedenle, ilk olarak patellofemoral ve tibiofemoral eklemlerden oluşan üç boyutlu dinamik bir diz modeli geliştirildi. Patolojiyi simüle etmek için patellar tendon uzunluğu orijinal uzunluğunun \%25'i ve \%50'si oranlarla artırıldı. Patoloji için normal ve DTTTS sonrası Tibiofemoral ve patellofemoral temas kuvvetleri, bağ demetleri üzerindeki yükler, tibial rotasyonlar ve kuadriseps etkinliği karşılaştırıldı. Bulgular: Sonuçlar, pattelar tendon uzaması olarak $10^{\circ}$ ila $20^{\circ}$ diz ekstansiyonu arasındaki medial tibiofemoral temas kuvvetinin ve $17^{\circ}$ ila $30^{\circ}$ arasindaki lateral tibiofemoral temas kuvvetinin kademeli olarak arttığını gösterdi. Bulgular, patella altanın bağ demetlerinin nötral gerginliğini değiştirdiğini, $0^{\circ}$ ile $17^{\circ}$ arasında medio-lateral diz stabilitesini azalttığını ve dizin çömelmeden ekstansiyonu sırasında patello-femoral temas kuvvetini ve kuadriseps kasının etkinliğini artırdığını göstermektedir. DTTTS bazı biyomekanik değişiklikleri normalize etse de yüksek fleksiyon açılarında iç rotasyon, tibianın valgus-varus rotasyonu ve aACL ve PCL gerginliği normalden farklı kalmıştır. Sonuç: $\mathrm{Bu}$ değişiklikler, tibiofemoral ve patellofermoral eklemlerde kıkırdak dejenerasyonunun gelişmesine katkıda bulunan bir rol oynayabilir. Yetersiz kuadriseps kuvveti ve bazı bağlardaki anormal yükleme paterni, DTTTS ameliyatından sonra çömelme yürüyüşünün tekrarlama mekanizmasına da katkıda bulunabilir.

Anahtar kelimeler: Ligament, diz, çömelme, patella alta, patellar tendon, üç boyutlu model

$\begin{array}{ll}\text { Geliş Tarihi: 26.01.2020 Kabul Tarihi: 05.12.2020 } & \text { Kan }\end{array}$

aIstanbul Kültür University, Faculty of Health Science, Physiotherapy and Rehabilitation Department, İstanbul, Türkiye, e-posta: n.akalan@iku.edu.tr ORCID: 0000-0001-9813-635X

bIstanbul University, School of Medicine, Department of Orthopedics and Traumatology, Istanbul, Turkey, e-posta: ytemelli@gmail.com

${ }^{\mathrm{c} B o g ̆ a z i c ̧ i ~ U n i v e r s i t y, ~ I n s t i t u t e ~ o f ~ B i o m e d i c a l ~ E n g i n e e r i n g, ~ I s t a n b u l, ~ T u r k e y, ~ e-p o s t a: ~} \underline{\text { mehmed@ @oun.edu.tr }}$

Sorumlu Yazar/Correspondence: N.Ekin Akalan e-posta: $\underline{\text { n.akalan@iku.edu.tr }}$

Atıf: Akalan NE, Temelli Y, Özkan M. Yüksekte patellası olan bir dizin tibial tüberkülün distale transfer cerrahisi sonrası squat ekstansiyon sırasındaki biyomekanik değişiklikleri. Săglık ve Yaşam Bilimleri Dergisi 2020;2(2):27-35.

Citation: Akalan NE, Temelli Y, Ozkan M. Knee biomechanics during squat rising with patella alta and after distal transfer of tibial tubercular surgery. Journal of Health and Life Science 2020;2(2):27-35. 


\section{INTRODUCTION}

Patella alta and increased patellar tendon length (IPTL) are common in children with cerebral palsy who walk in crouch gait pattern. Patella alta is described in clinic as longer patellar tendon than the length of the patella. $^{1,2}$

Crouch gait pattern is a complex, multi-level disorder, characterized by exaggerated dorsiflexion of the ankle with flexion of the knee and hip during stance phase. Weak muscle groups that maintain erect posture such as hip extensors, vasti, soleus muscles and spasticity of the hamstring and iliopsoas, play primary role on developing crouch gait posture in early years in cerebral palsy. ${ }^{3,4}$ Over time, hip and knee extensors become inadequate to prevent crouch posture and consequently patella alta, excessive energy consumption, failure of patellar mechanism, excessive stress and strain on the joints, knee pain, fragmentations and stress fractures on patella and tibial tubercle develops, which make the walk impossible in adolescence period of growth. ${ }^{1}$

Although some patients demonstrate noticeable improvement with the surgery, yet some others have little or no improvement, if not get worse. ${ }^{1,3}$ The treatment is even more difficult when crouch gait is firmly established in the midst of the adolescent growth spurt. ${ }^{1}$ The biomechanical reasons of continuing excessive hip and knee flexion after the treatment are unclear. $^{3}$

Over the year's patella alta alters the normal biomechanical response of the ligaments and contact surfaces, creating excessive abnormal load on some areas on joint surfaces, and changing the normal kinematic behavior of the knee joint which may even worsen the existing abnormalities. Recurrence mechanism of crouch gait pattern can also be a result of biomechanical alterations. ${ }^{1,2}$

Shortening of the quadriceps mechanism is one of the common surgical approach for treating crouch posture, which is performed surgically by transferring the tibial tubercle distally (DTTTS) or patellar tendon placation procedures. ${ }^{5}$ The aim is to match inferior pole of the patella with the joint line. ${ }^{6}$ Neither the affects of patella alta on the three dimensional knee extensor mechanics, nor the biomechanical changes after quadriceps shortening procedure has not yet been studied. ${ }^{2}$

In this study we investigated the biomechanical consequences of elongated patellar tendon length during squat extension. To compare the alterations of the tibiofemoral contact forces, the tensions on the ligament bundles and tibial rotations for the knee with normal, IPTL and surgically treated patellar tendon length (PTL), a three dimensional tibiofemoralpatellofemoral (TPF) model was simulated.

\section{METHODS}

We studied the tibiofemoral model and tested by comparing the tibial rotation, translation and contact forces during passive knee flexion earlier (Figure 1). ${ }^{7}$ A three-dimensional patellofemoral model was simulated and integrated to the tibiofemoral model. First the kinematic behavior of the knee model was examined during the knee extension. for normal patellar tendon length (PTL). Next squat extension is simulated for knee with normal; patella alta; and after DTTTS. As a final step, the knee biomechanics with IPTL, DTTTS and normal PTL were compared.
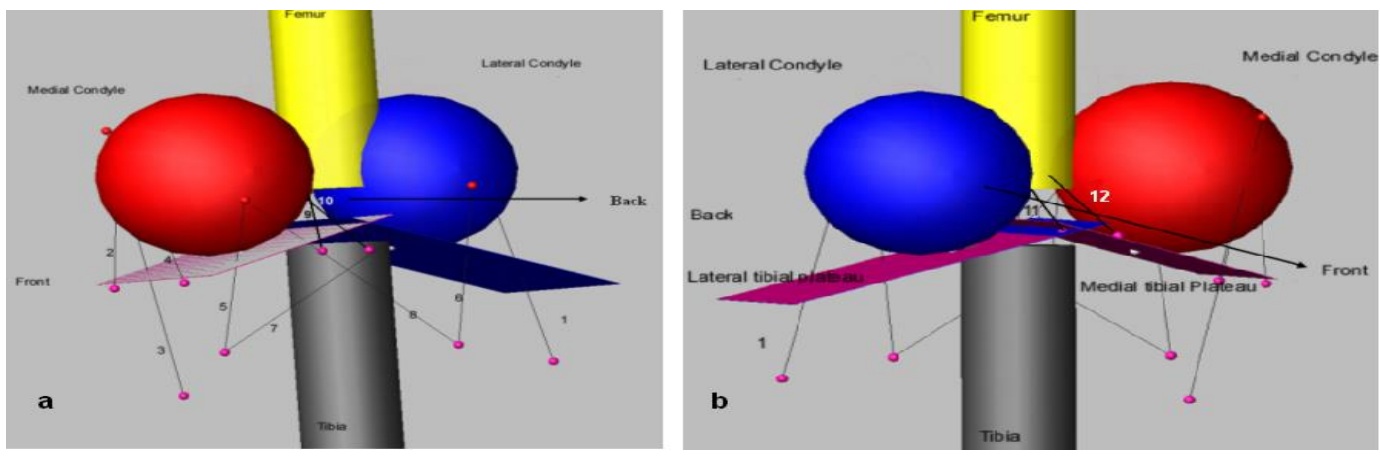

Figure 1. Reconstruction of tibiofemoral model: The back-oblique (a) and front-oblique (b) views of tibiofemoral model The back-oblique (a) and front-oblique (b) views of tibiofemoral model, 1) LCL: Lateral Colleteral Ligament, 2) aMCL: Anterior bundle of Medial Colleteral Ligament, 3) dMCL: Deep bundle of Medial Colleteral Ligament,4) oMCL: Oblique bundle of Medial Colleteral Ligament,5) MCP: Medial Capsule of Popliteal ligament, 6) LCP: Lateral Capsule of Popliteal ligament, 7) OPL: Oblique Popliteal ligament, 8) APL: Arcuate Popliteal Ligament, 9) aPCL: Anterior bundle of Posterior Cruciate Ligament, 10) pPCL: Posterior bundle of Posterior Cruciate Ligament, 11) pACL: Posterior bundle of Anterior Cruciate Ligament, 2) aACL: Anterior bundle of Anterior Cruciate Ligament. 


\section{Reconstruction of Tibiofemoral Model}

Thirteen ligament bundles were defined between femur and tibia are; anterior and posterior portions of anterior cruciate ligaments (aACL, pACL) and posterior cruciate ligament (aPCL, pPCL), anterior, deep and oblique bundles of medial collateral ligament (aMCL, dMCL, oMCL), lateral collateral ligament (LCL), medial and lateral fibers of posterior capsule (MCP, LCP), and oblique and arcuate popliteal ligaments (OPL, APL). ${ }^{7,8}$ The attachments and the physical properties of the ligaments were adopted from elsewhere. ${ }^{8}$ Three dimensional deformable contactsand friction force coefficients (0.04) were described between the articulating geometries. ${ }^{9-11}$

\section{Constructing Patellofemoral Model}

Distal femoral geometric shape was constructed according to a cadaver study. ${ }^{12}$ (Figure 2). Because the individual changes of the mean sulcus angle in different femur cadavers are small, it was assumed to be constant, $146^{\circ}$ in the present study.

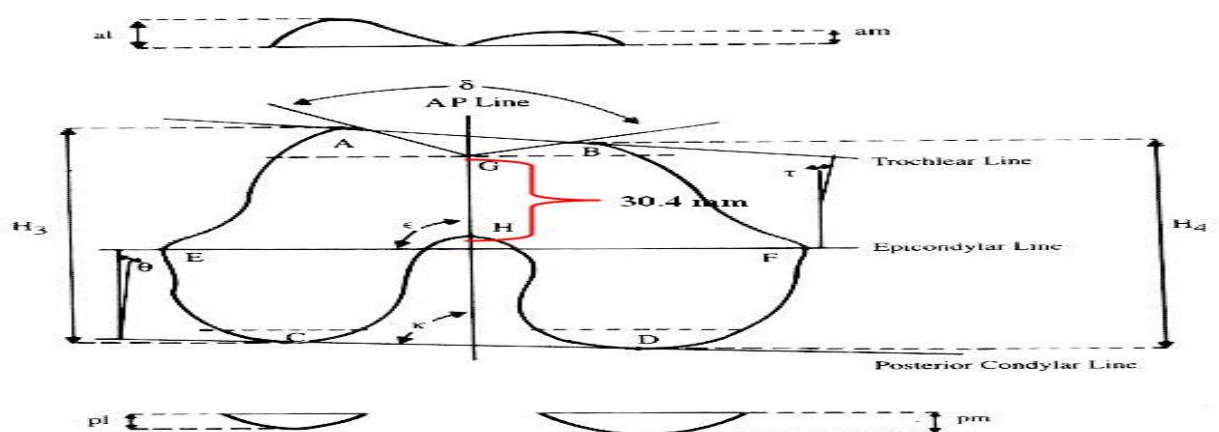

Figure 2. Constructing patellofemoral model: The anterior tip points of lateral (A) and medial (B) femoral condyles, the troclear line(AB), the posterior tip points of the lateral (C) and medial (D), the posterior condylar line (CD), femoral condyles, the deepest point of the throclar groo ve (G), the center of intercondylar notch $(\mathrm{H})$, the anterior posterior line $(\mathrm{GH}=30.4 \mathrm{~mm})$, sulcus angle (AGB), AP line- epicondilar line angle $(\epsilon)$, AP line-posterior condylar line angle $(\kappa)$, epicondylar lineposterior condylar line angle $(\theta)$, trochlear line-epicondylar line angle $(\tau)$, lateral condylar height $(\mathrm{H} 3)$, medial condylar height (H4), anterior lateral cut (al), posterior lateral cut (pl), anterior medial cut (am), posterior medial cut (pm) [Shih 2004] (Reprinted with the permission of Elsevier Publishing Company, Inc.).

Patella has two axes; $(3.94 \mathrm{~cm}$ length, $1.63 \mathrm{~cm}$ depth), ${ }^{11,13}$ and a plane which is bounded around the intercondylar groove (Figure 3). This plane is extended along the sulcus for resulting in a patellar length of 3.94 $\mathrm{cm}$. The inertial patellar parameters were taken from elsewhere. ${ }^{10}$

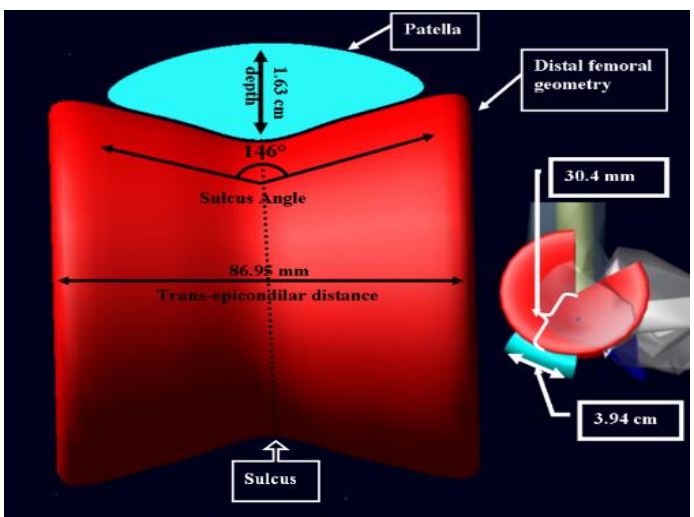

Figure 3. Axial and sagittal view of patellofermoal joint model in the presen study

Patellar tendon (PT) was represented as three linear springs as illustrated in Figure $4 .{ }^{14}$ The force on PT is; ${ }^{6}$

$$
F_{p}=k_{p}\left(L_{p}-L_{\mathrm{O}_{p}}\right)
$$

where $\mathrm{F}_{P}$ is the patellar tendon force, and $k_{p}, L_{p}, L_{0 p}$ are the stiffness $(200 \mathrm{~N} / \mathrm{mm})$, the current length and the slack length of the patellar ligament respectively. The slack length $L_{0 p}$ was specified to allow a ratio of 0.6 between the patellar ligament force and the quadriceps force at $90^{\circ}$ knee flexion. ${ }^{6}$

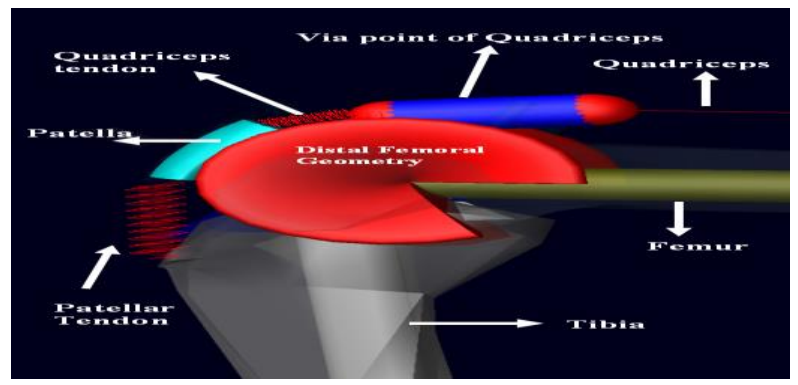

Figure 4. Sagittal view of patellofermoal and tibiofemoral joints; linear spring representation of patellar tendon and quadriceps tendon and single line representation of the quadriceps muscle.

The attachment points of PT on patella and tibial tuberosity were adopted from the literature. ${ }^{15}$

Quadriceps was represented as a single line force which was assumed to be parallel to the femur. ${ }^{6}$ Quadriceps tendon was represented by three linear springs with the same patellar tendon coefficients. ${ }^{14}$ The contact force between quadriceps tendon and distal femur is described through two massless spheres acting as via points were introduced as shown in Figure 4. The wrapping point is located where the patellar tendon should normally contact to the distal femur which is at $70^{\circ}$ knee flexion. In this simulation of squat rising the range of knee flexion is between 10 to $30^{\circ}$. Although this range of knee motion seems to be way out of quadriceps contact range, it is appropriate for the analysis of the mild and moderate level crouch gait patterns. ${ }^{1}$ Moreover, we can refer to the knee 
biomechanics in this range that was previously validated in elsewhere. ${ }^{10}$

The TPF model was tested by simulating the knee extension exercise. The initial positions were defined according to the experimental data available in the literature. ${ }^{6}$ Accordingly quadriceps generate $400 \mathrm{~N}$ mean force during knee extension.

Once the patellar rotations, translations and tibiofemoral contact forces on the medial and lateral compartments during knee extension exercise were found satisfactory, $6,9,13,15$ the TPF model was utilized for the simulation of dual limb squat extension exercise as in Figure 5. ${ }^{10}$

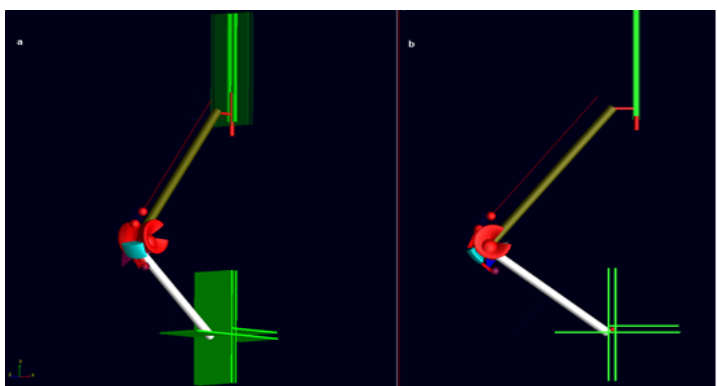

Figure 5. Oblique (a) and sugittal (b) views of the knee model during the simulation of squat extension

The hip joint was represented with a combination of revolute and translational joint which slides vertically during the simulation of squat rising. The ankle joint model allows free medio-lateral translation, valgusvarus, internal-external rotations and flexionextension. However, the antero-posterior and superiorinferior movements of the ankle joint were restricted. ${ }^{10}$ Simulation of dual limb squat extension with normal PTL, IPTL and surgically treated IPTL.

Knee was described in full extension when the hip was at $0^{\circ}$. Both knee and the hip joints are $90^{\circ}$ when the femur is parallel to the ground. A constant vertical load $(200 \mathrm{~N})$ was applied to the hip during the entire simulation. The single force representing the quadriceps muscle in the model was used to extend the knee joint. During the squat extension, quadriceps acted parallel to the femoral axis and its force- knee angle relationship was defined according to the literature. ${ }^{10}$

The biomechanical changes during squat extension were analyzed by utilizing the above described TPF model for four different conditions; i) with normal (3.94 cm) PTL, ii) elongated PTL with $25 \%$ and iii) elongated PTL with $50 \%$, iv) for a simulation of DTTT surgery on the $50 \%$ extended PTL. The surgical simulation is the displacement of the distal end of the PT along the long axes of the tibia, distally. Displacement aims the alignment of the inferior pole of the patella close to the joint line. The simulation of squat extension was repeated for all the four scenarios comparing the results with the findings of normal PTL, IPTL and DTTTS.

Since, the present study aimed to investigate the biomechanical consequences of patella alta theoretically by a computerized simulation three dimensional model, no actual patient was participated and, therefore, no approve from the ethical committee was necessary.

\section{RESULTS}

\section{Validation of the Patellofemoral Model}

Patellar rotations, patellar translations and tibiofemoral contact forces during the simulation of knee extension exercise were compared with the literature for the normal PT. In the literature patellar flexion is described as an almost linear function of the knee flexion reaching $60^{\circ}$ at $90^{\circ}$ knee flexion, as simulated (Figure 6). Patellar tilt and patellar rotation are reported to be in between $0-5^{\circ}$ as in literature..$^{6,9,15}$

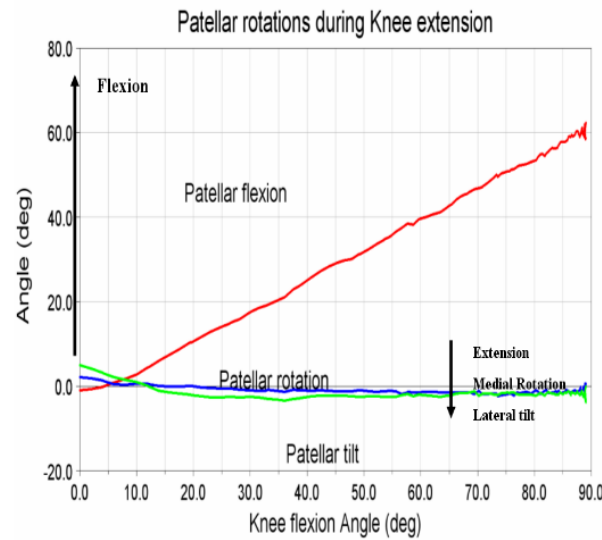

Figure 6. Patellar rotations; patellar flexion, extension and tilt during the simulation of knee extension

Patellar displacements were also in agreement with the literature ${ }^{9}$ as shown in Figure 7.

The tibiofemoral contact force on medial compartment was found as always larger than the lateral compartment as expected (Figure 8). 6 The force on the medial component is roughly twice as large of the lateral compartment also as anticipated, during the last $30^{\circ}$ knee extension. ${ }^{4}$

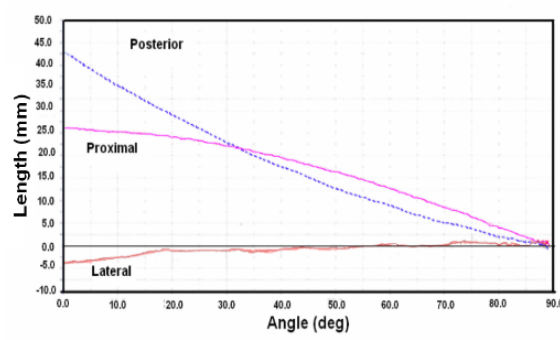

Figure 7. Posterior (dashed line), proximal and lateral (solid lines) displacement of the patella 


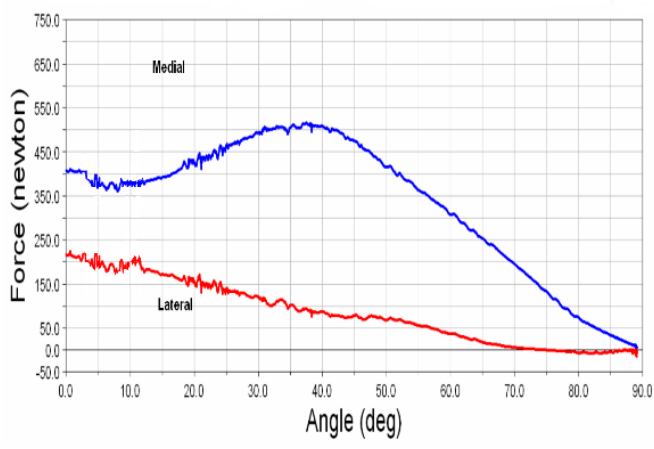

Figure 8. Illustration of contact forces on medial and lateral compartments of the tibia during knee extension

\section{The Outcomes of the Squat Rising}

Tibiofemoral contact forces, ligament bundle loads and tibial rotations were analyzed during simulation of squat extension of the knee with normal, $25 \%$ and $50 \%$ elongated PTL, and surgically treated IPTL.

Between $10^{\circ}$ to $23^{\circ}$ knee flexion, the medial tibiofemoral contact force increased as a result of patellar tendon elongation. Lateral tibiofemoral contact force increased gradually by extending PTL between $17^{\circ}$ to $30^{\circ}$ as shown in Figure 9.

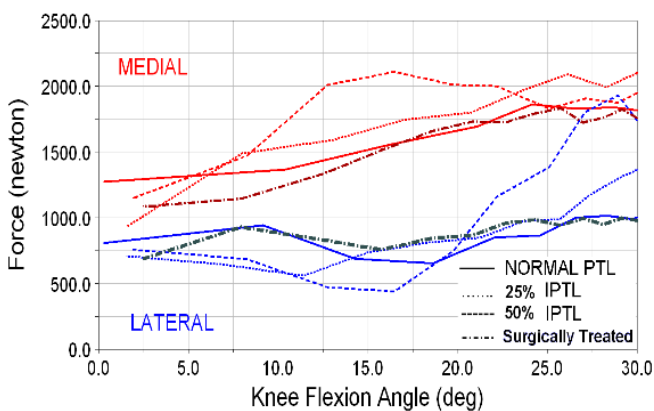

Figure 9. Medial and lateral contact forces during simulation of squat extension with different PTL and after distal tubercular surgery.

By elevating the patella, the tension on ACL had a tendency of increasing for a specific range of knee extension. Figure 10 illustrates the tension on aACL increased at higher flexion angles due to the elongation. The rise of tension on pACL, however was seen for the lower flexion angles.

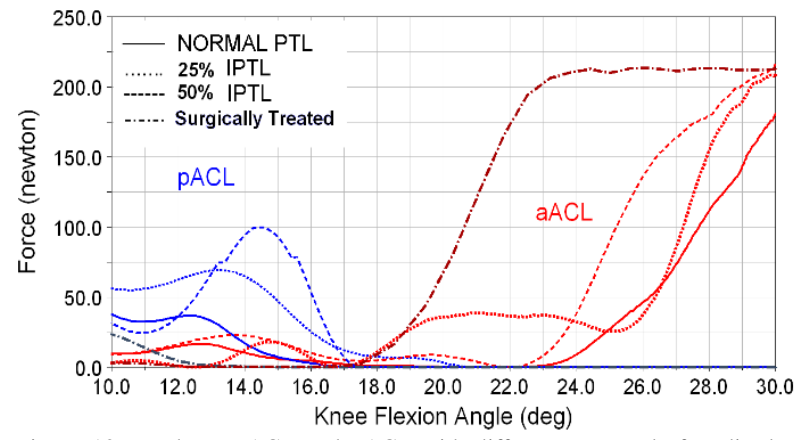

Figure 10. Loads on aACL and pACL with different PTL and after distal tubercular surgery.
For the knee with the $50 \%$ longer PTL the loads on aPCL was higher than the normal for lower knee flexion angles (between 20-25 ), however, pPCL force increased at higher flexion angles and the peak force about 3 fold higher than normal (from 155 to $149 \mathrm{~N}$ ) (Figure 11).

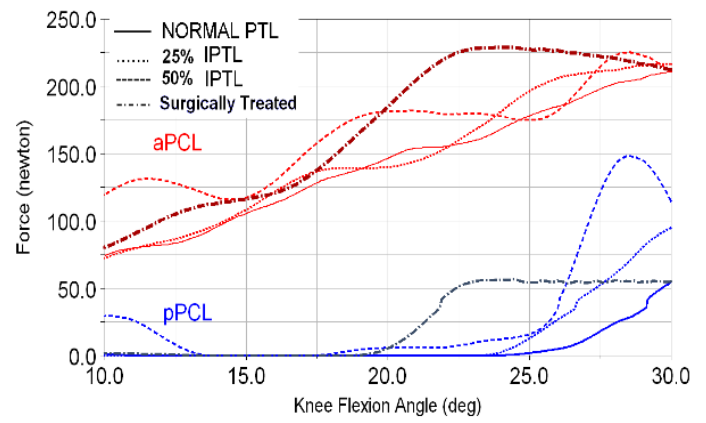

Figure 11. Loads on aPCL and pPCL with different PTL and after distal tubercular surgery

As the patellar tendon length elongates the peak tension of aMCL increased (Figure 12). The peak force of aMCL enlarged from 154 to $300 \mathrm{~N}$ between 25 to $30^{\circ}$ knee extension. For the $50 \%$ extended PTL the load on the dMCL is lower than the normal between $10^{\circ}$ to $23^{\circ}$ knee extension,but gets larger at higher flexion angles (Figure13).

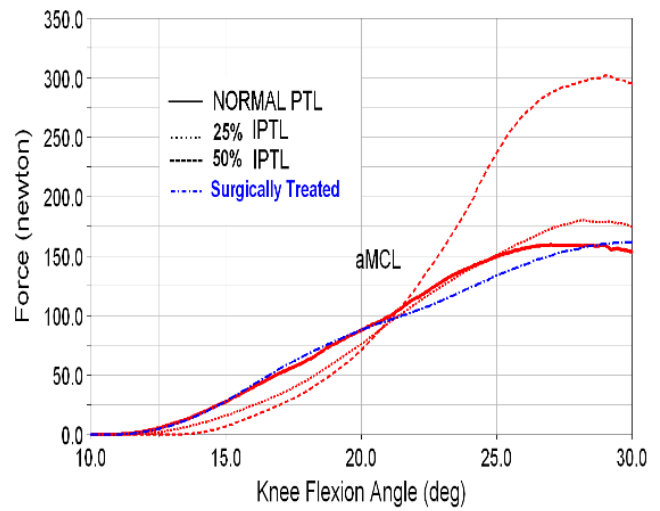

Figure 12. Loads on aMCL with different PTL and after distal tubercular surgery

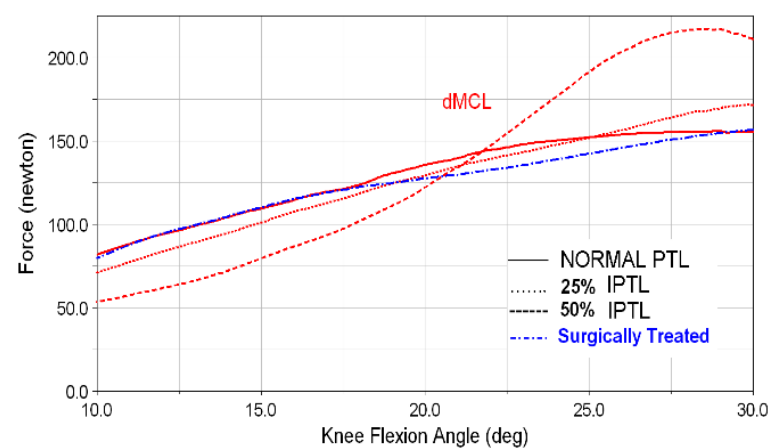

Figure 13. Loads on dMCL with different PTL and after distal tubercular surgery

As PT length was extended, the force on the LCL not only peaked at lower knee flexion angles but also started loading at higher extension angles compared to 
normal PTL (Figure 14). For 50\% of PTL elongation, the LCL tension was three-fold higher than normal length. The load changes due to tendon length were negligible for the rest of the ligament bundles.

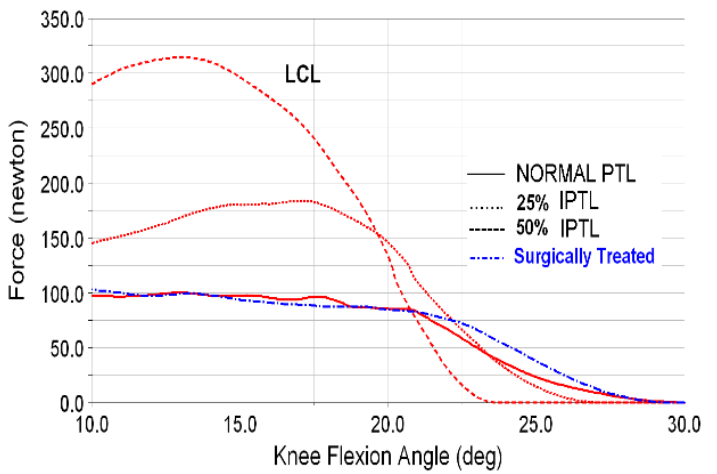

Figure 14. Load on LCL with different PTL and after distal tubercular surgery

Even though the internal tibial rotation was higher than the normal for the elongated PTL for the lower knee flexion angles, the tibial rotation decreased at higher flexion angles (Figure 15). Similarly, peak varus rotation of the tibia was higher in between $0^{\circ}$ to $17^{\circ}$ (from around 1.5 to $5.5^{\circ}$ knee extension), although it diminished and turned in to peak valgus rotation ( 1 to $\left.-5.5^{\circ}\right)$ at higher flexion angles (Figure 16).

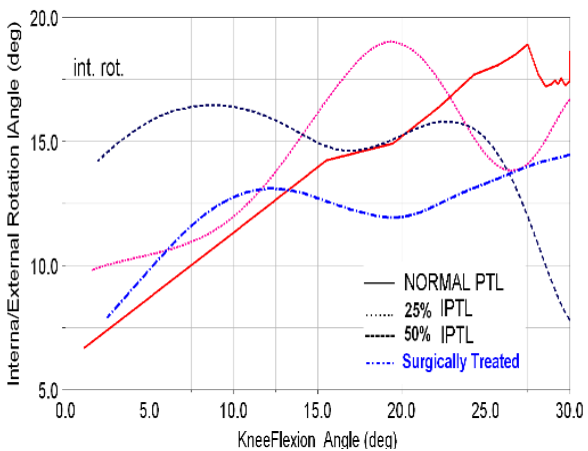

Figure 15. Internal and external rotation of the tibia during squat extension with different PTL and after distal tubercular surgery

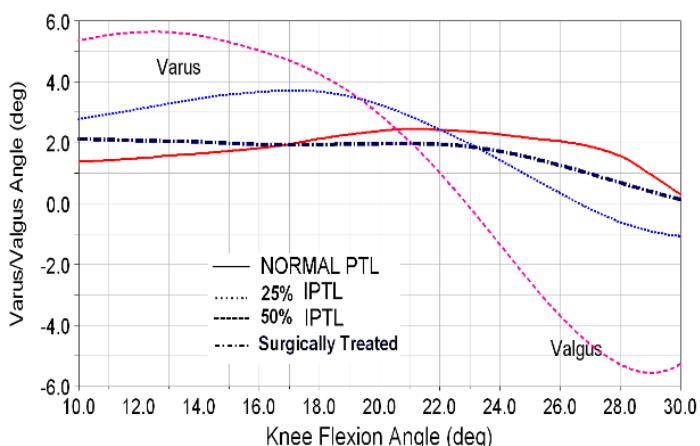

Figure 16. Varus and valgus rotations of the tibia during squat extension with different PTL and after distal tubercular surgery
The patellofemoral compression force rises as the flexion angle increases. But that increase is progressively higher as PT is elongated. For 50\% PTL elongation the tension rises from $2250 \mathrm{~N}$ to $2750 \mathrm{~N}$. The increase is more dominant at the higher knee flexion angles (Figure 17) and the maximum quadriceps force decreased from $2035 \mathrm{~N}$ to $2000 \mathrm{~N}$ and prompted by elongating PTL (Figure 18).

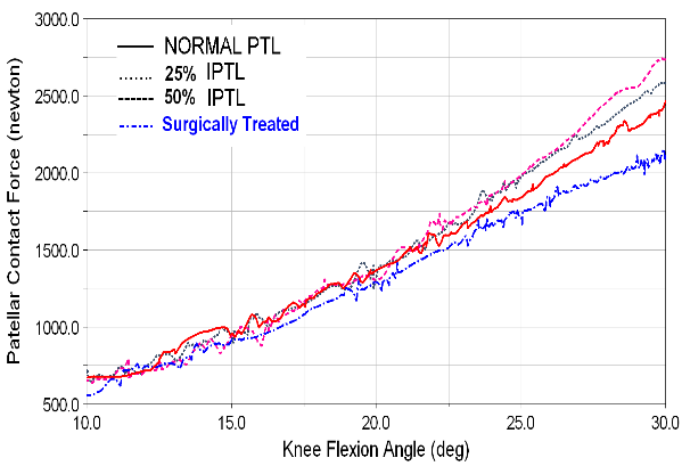

Figure 17. Patellar contact force during squat with different PTL and after distal tubercular surgery

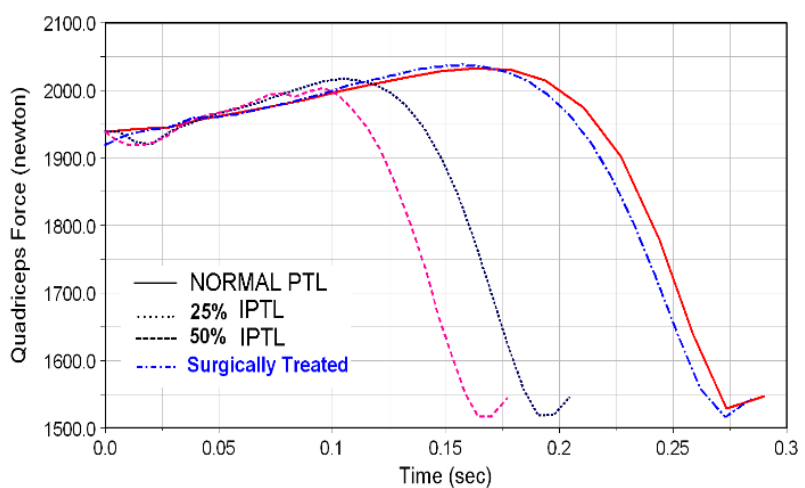

Figure 18. The peak values of quadriceps force decreased and time of reaching the peak forces shorted with IPTL. The knee extension was quicker than normal for the knee with distal tibial tubercular transfer surgery

As a result of DTTTS most of the ligament tension for the squat rising could approach to the normal. However, the loads on aACL and on the bundles of PCL remained slightly different than the normal. Although was closer to the normal compared to the extended PTL, DTTTS produced different varus/valgus and internal/external rotations (Figures 15 and 16). After DTTTS, the peak varus and valgus angle was still higher than normal (2.5 and 0.5 for normal and $3.8^{\circ},-1^{\circ}$ after DTTTS respectively). Between 30 to $15^{\circ}$ knee flexion, after the DTTTS, the internal rotation was about lower than normal.

\section{DISCUSSION}

\section{Validation of the Tibio-patello-femoral Model}

The results of normal knee extension exercise simulation are agreed with the literature..$^{6,9,13,15}$ (Figure 
$6,7,8)$. Although the existence of some discrepancies with the reference model ${ }^{8}$, however do not exist when compared with the natural kinematics of the tibiofemoral ${ }^{7}$ and the patellofemoral,,${ }^{9,11}$ joint contact forces for both compartments are match with the literature. $^{6}$

\section{Simulation of Squat Extension with Different PTLs}

The contact force on medial compartment is higher than the lateral for normal positioned patella which is in agreement with the literature. ${ }^{16}$

We can conclude that as a result of IPTL the mediolateral stability of the knee is distorted noticeably (Figure 9). The asymmetric loading between medial and the lateral compartments of the knee can be associated with the rotational instability in frontal plane (Figure 16). The elevation of varus rotation corresponded with the escalation of medial contact force, and the increase of valgus rotation is related with the rise of lateral contact force. These tibiofemoral alterations have been hypothesized to contribute the cartilage degeneration and knee osteoarthritis. ${ }^{16}$ When the other daily activities such as walking, squatting or even jumping are considered, it may cause a destructive effect on tibiofemoral joint cartilage for patients with patella alta.

On the other hand, the reason of coronal plane instability may due to the extra degree of freedom of ankle joint on medio-lateral direction. This characteristic of the simulation is inherited from the model. ${ }^{10}$ However, this behavior of the ankle provided normal squat knee extension performance for normal positioned patella. Therefore, we can assume that patella alta alters the medio-lateral behavior of the knee as well as the ankle.

According to DTTTS simulations tibiofemoral compressive forces can be corrected. Therefore, DTTTS can be decided for crouch gait patients with patella alta at an earlier stage of the growth, before articular degenerations and altered ligament tensions emerge.

Figure 18 illustrates that, as PTL increased, quadriceps can complete the same extension range with lower amount of quadriceps peak force in shorter time compared to a normal extension. This indicates that quadriceps are used more efficiently for IPTL patients as described in literature. ${ }^{2,13,17}$ The force-time relationship of quadriceps force returned to normal as a result of DTTTS (Figure 18). This requires a stronger quadriceps muscle contraction yielding a knee extension closer to the normal. Although children with cerebral palsy could stand more effectively with less quadriceps force, they may not be able to produce the higher quadriceps force required after DTTTS. ${ }^{18}$ As a result, the expected knee extension can never be achieved due to lack of quadriceps force. These inadequate quadriceps force may contribute the recurrence mechanism of crouch gait after the orthopedic surgeries. In such case the incomplete knee extension should not be attributed to a failed DTTTS but rather to weakness in quadriceps muscle.

When we analyze the results, although closer to a normal knee extension, DTTTS produced slightly different motion in general. Our findings support the theory that the surgery attempted to equalize the quadriceps moment arm and patellar tendon moment arm as it is seen in the intact knee, ${ }^{2}$ but the quadriceps leverage remained dominant even after the surgery. The increased anterior directed force is resisted by enlarged ACL tension at higher flexion angles ${ }^{19,20}$ as it was illustrated in Figure 10. As ACL load increases, external rotation of the tibia ${ }^{3}$ increases (Figure 15). By the surgery, patellofemoral compressive force is slightly under the normal. The DTTTS may decrease the patellar tendon moment arm $\left(\mathrm{SM}_{\mathrm{pl}}\right)$ as illustrated simply in Figure 19. As the tubercle transferred distally, in sagittal plane, the angle of the patellar tendon relative to the tibia decreases from $(\beta)$ to $(a)$, therefore patellar moment arm and patellofemoral contact force is reduced as stated elsewhere. ${ }^{2,13}$ For higher knee flexion angles, reduced patellofemoral contact force results in higher force transmission from quadriceps to patellar tendon.

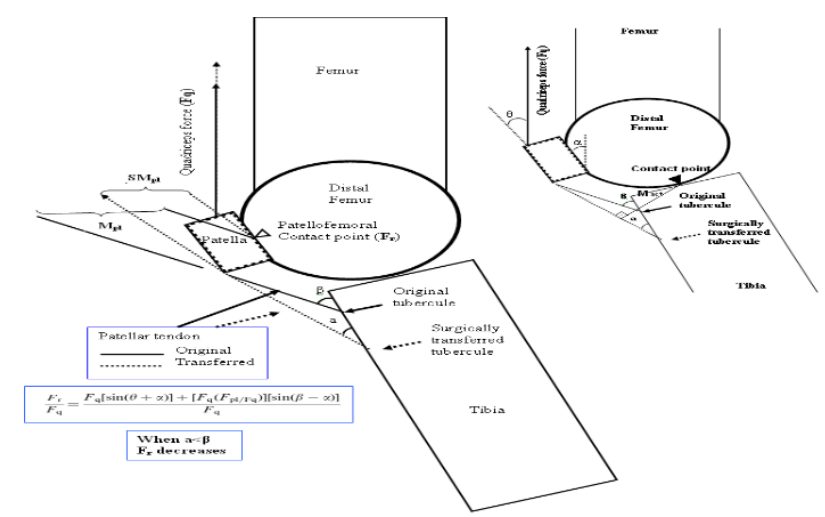

Figure 19. Diagram of the sagittal view of the knee model. With distal tubercular transfer, the angle of the patellar tendon relative to the tibia $(\beta)$ decreases (a), therefore patellofemoral contact force (Fr) diminishes and transferred force from quadriceps $(\mathrm{Fq})$ to patellar tendon $(\mathrm{Fpl})$ increases. ${ }^{19}$

Although the tibial rotations became closer to normal as a result of DTTTS, the internal rotation was found as lower and the excursion of the valgus-varus rotations were still slightly higher than normal for high knee flexion angles (Figure 15, 17). The new distal attachment of the patellar tendon may be the reason for the rotational instability (internal-external and valgusvarus) of the knee because it alters the normal loading 
pattern of the ligaments. By the surgery, increased force transmission from quadriceps to tibia, as we mentioned earlier, may tighten the aACL which causes diminished internal rotation and contribute the frontal plane instability. ${ }^{3}$

The ACL loading pattern during squatting is questionable. In Ecamilla's work (2000), it was argued no ACL force during squatting, however several studies stated the existence of tensional force on ACL during squatting. ${ }^{16,19,21}$ The reason of the existence of ACL load in our study might be the absence of the primary muscles that produce posterior directed force during squatting such as hamstrings and gastrocnemius. ${ }^{21}$ On the other hand, most of these muscles are tight for children with cerebral palsy and can generate excessive posterior directed force on tibia. To analyze the biomechanical alterations of patella alta and DTTTS in detail, a knee model which includes other relevant muscles should be included.

The PCL force progressively increased for higher flexion angles for normal knee as reviled in literature. ${ }^{19,21}$ (Figure 11). Increased tensional load on pPCL in lower flexion angles and earlier initiation of loading pattern on aPCL could be due to induced valgus rotation which is primarily resisted by medial collateral ligaments and PCL. ${ }^{22}$ Figure 16 illustrates that as elongation of patellar tendon, the knee flexion angles where the valgus rotation increase coincided with the augmentation of tensional force on dMCL, aMCL, and PCL (Figure 11, 12, 13). To resist the medial directed force (varus rotation in frontal plane), the tension on LCL and ACL increases ${ }^{22}$ as also illustrated in Figure 10, 14 and 16.

As agreed with the literature, the patellar contact force increased as the patellar tendon elongation which may cause cartilage deformation between trochlea and the patella and generate anterior knee pain. ${ }^{23,24}$

The meniscus and the other ligaments that attach meniscus to tibial plateau and patella to knee capsule were also not included because of their complexity of the structures. ${ }^{7,10}$ Besides these limitations, the model represented the natural biomechanical behavior of the normal knee during the simulations of knee extension exercise and squat rising. Future cadaver or MRI validation studies to verify our DTTTS findings would be helpful to justify our statements.

\section{CONCLUSION}

These findings suggest that patella alta should be corrected by the surgical interventions such as distal transfer of tibal tubercule, before the irreversible tibiofemoral and patellofemoral cartilage degenerations settle which can cause the osteoarthritis for children with cerebral palsy in adult spurt of growth. Furthermore, postoperative quadriceps muscle weakness and abnormal loading patterns on ligaments after DTTTS may play a contributory role of recurrence of crouch gait pattern.

\section{ACKNOWLEDGMENTS}

This project is supported in part by TUBITAK. Grant number 104 S508.

\section{REFERENCES}

1. Stout J. Novacheck TF, Gage J. Treatment of crouch gait. In: Gage, JR, Schwartz MH, Koop S, Novacheck TF. The Identification and Treatment of Gait Problems in Cerebral Palsy, 2nd. Mac Keith Press, London, UK 2009:555-578.

2. Ward SR, Terk MR, Powers M. Influence of patella alta on knee extensor mechanics. Journal of Biomechanics. 2005;38:24152422.

3. Brady MF, Bradley MP, Fleming BC, Fadale PD, Hulstyn MJ, Banerjee R. Effects of initial graft tension on the tibiofemoral compressive forces and joint position following ACL reconstruction. Am $J$ Sports Med. 2007;35(3):395-403.

4. Õunpuu S, Gage JR, Davis RB. Three dimensioal lower extremity joint kinetics in normal pediatric gait. J Pediatr Orthop. 1991; 11:341-349.

5. Miller F. Knee, leg and foot. In: Miller F. Cerebral palsy, Springer, USA, Newyork; 2005:667-805.

6. Caruntu DI, Hefzy MS. 3-D anatomically dynamic modeling of the human knee to include tibio-femoral and patello-femoral joints. Journal of Biomechanical Engineering. 2004;126 (1):44-53.

7. Akalan NE, Ozkan M, Temelli Y. Threedimensional knee model: Constrained by isometric ligament bundles and experimentally obtained tibio-femoral contacts. Journal of Biomechanics. 2008;41:890-896.

8. Abdel-Rahman EM, Hefzy MS. Threedimensional dynamic behavior of the human knee joint under impact loading. Journal of Biomechanics. 1998;20:276-290.

9. Chew JTH, Strewart NJ, Hanssen AD, Luo PZ, Rand JA, An KN. Differences in patellar tracking and knee kinematics among three different total knee designs. Clinical Orthopaedics and Related Research. 1997;345:87-98.

10. Guess TM, Maletsky LP. Computational modelling of total knee prosthetic loaded in a dynamic knee simulator. Medical Engineering \& Physics. 2005;27:357-367.

11. Van Eijden TMGJ, Kouwenhoven E, Verburg J, Weijs WA. A mathematical model of the patello-femoral joint. $J$ Biomech. 1986;19(3):219-229.

12. Shih YF, Bull AMJ, Amis AA. The cartilaginous and geometry of the femoral 
trochlear groove. Knee Surgery, Sports Troumatology, Artroscopy. 2004;12:300-306.

13. Yamaguchi GT, Zajac FE. A planar model of the knee joint to characterize the knee extensor mechanism. Journal of Biomechanics. 1989;22:1-10.

14. DeFrate LE, Nha WK, Papannagari R, Moses JM, Gill TJ, Li G. The biomechanical function of the patellar tendon during inüvivo weight-bearing flexion. Journal of Biomechanics. 2007;40:1716-1722.

15. Hirokawa S. Three-dimensional mathematical model analysis of the patellafemoral joint. Journal of Biomechanics. 1991;24(8):659671.

16. Zhang Y, Hunter DJ, Nevitt MJ, et al. Association of squatting with increased prevalence of radiographic tibiofemoral knee osteoarthritis. Arthritis \& Rheumatism. 2003;50(4):1187-1192.

17. Bertollo N, Pelletier MH, Walsh WR. Simulation of patella alta and the implications for in vitro patellar tracking in the ovine stifle joint. J Orthop Res. 2012;30(11):1789-1797.

18. Damiano DL, Kelly LE, Vaughn CL. Effects of quadriceps femoris muscle strengthening on crouch gait in children with spastic diplegia. Phys Ther. 1995;75(8):658-667.

19. Toutoungi DE, Lu TW, Leardini A, Catani F, O'Connor J. Cruciate ligament forces in the human knee during rehabilitation exercises. Clinical Biomechanics. 200;15:176-187.
20. Akgün AS, Agirman M. Associations between Anterior Cruciate Ligament Injuries and Patella Alta and Trochlear Dysplasia in Adults Using Magnetic Resonance Imaging. $J$ Knee Surg. 2020 Mar 4. doi: 10.1055/s-00401702198.

21. Escamilla RF, Knee biomechanics of the dynamic squat exercise. Official Journal of the American College of Sports Medicine. 2001;33(1):127-141.

22. Piziali RL, Seering WP, Nagel DA, Schurman DJ. The function of the primary ligaments of the knee in atrior-posterior and medial-lateral motions. J Biomechanics. 1980;13:777-784.

23. Luyckx T, Didden K, Vandenneucker H, Labey L, Innoceti B, Bellemans J. Is there a biomechanical explanation for anterior knee pain in patients with patella alta? influence of patellar height on patellofemoral contact force, contact area and contact pressure. $J$ Bone Joint Surg Br. 2009;91(3):344-350.

24. Fitzpatrick CK, Baldwin MA, Laz PJ, et al. Development of a statistical shape model of the patellofemoral joint for investigating relationships between shape and function. $J$ Biomech. 2011;44:2446-2452. 